\title{
LOS ACUERDOS ATRIBUTIVOS DE JURISDICCÓN A FAVOR DE UN TRIBUNAL EXTRANJERO INCLUIDOS EN UN CONOCIMIENTO DE EMBARQUE: LOS USOS Y LA LIBERTAD CONTRACTUAL EN EL SECTOR MARITIMO. COMENTARIO AL AUTO DE 5 DE JULIO DE 2019 DE LA AAP DE MADRID (SECCION 28)
}

\author{
AGREEMENTS CONFERRING JURISDICTION IN FAVOUR \\ OF A FOREIGN COURT INCLUDED IN A BILL OF LADING: \\ COSTUMS AND CONTRACTUAL FREEDOM IN THE \\ MARITIME SECTOR. COMMENTARY ON THE ORDER \\ OF 5 JULY 2019 OF THE AAP DE MADRID (SECTION 28)
}

\author{
Nerea Magallón Elósegui \\ Profesora Investigadora Ramon y Cajal \\ Universidad del País Vasco (UPV/EHU)
}

Recibido: 17.12.2019 / Aceptado: 13.01.2020

DOI: https://doi.org/10.20318/cdt.2020.5208

\begin{abstract}
Resumen: Los acuerdos atributivos de jurisdicción a favor de un tribunal extranjero incluidos en un conocimiento de embarque se han utilizado tradicionalmente en el sector marítimo como mecanismo que agiliza la práctica comercial a la vez que busca el equilibrio entre las partes que resolverán sus controversias ante un foro neutral y especializado. Sin embargo, la presencia de estas cláusulas en contratos estandarizados fomenta la discusión acerca de la existencia de una parte débil en la relación y la imposición de la cláusula sin su consentimiento y en detrimento de sus intereses. En esta decisión se vislumbra la dicotomía que ha resurgido a raíz de la nueva Ley de Navegación marítima que, con el objetivo de evitar los abusos inherentes a las cláusulas de sumisión sufridos por terceros poseedores de conocimientos de embarque, incorpora estrictas exigencias que alteran la línea seguida por la normativa europea.

Palabras clave: Derecho Internacional privado, artículo 25 Reglamento 1215/2012 (Bruselas I bis), clausulas atributivas de jurisdicción, autonomía de la voluntad de las partes.

Abstract: Jurisdiction agreements in favour of a foreign court included in a bill of lading have traditionally been used in the maritime sector as a mechanism that streamlines commercial practice while seeking a balance between the parties that will resolve their disputes in a neutral and specialized forum. However, the presence of these clauses in standardized contracts encourages discussion about the existence of a weak party in the relationship and the imposition of the clause without its consent and to the detriment of its interests. In this decision both positions are glimpsed reflecting a dichotomy that has resurfaced as a result of the new Law of Maritime Navigation which, with the aim of avoiding the abuses inherent in the submission clauses suffered by third parties possessing bills of lading, incorporates strict requirements that alter the line followed by the European regulations.
\end{abstract}

Keywords: Private international law, article 25 R 1215/2012 (Brussels I bis), clauses conferring jurisdiction, autonomy of the will of the parties. 
Sumario: I. Introducción. II. Hechos. III. Determinación del Derecho aplicable y tribunales susceptibles de elección. 1. El Derecho aplicable a la validez de la cláusula de sumisión. 2. Tribunales susceptibles de elección IV. Condiciones formales de validez del acuerdo atributivo de jurisdicción. V. Oponibilidad frente a terceros VI. Conclusiones.

\section{Introducción}

1. El Auto de la Audiencia Provincial de Madrid de 5 de julio de 2019 vuelve a poner encima de la mesa el debate sobre el alcance y los límites de las cláusulas atributivas de jurisdicción contenidas en un conocimiento de embarque. La autonomía de la voluntad en la contratación marítima internacional adquiere especificidades inherentes al ámbito en el que se articulan que han ido perfilándose a través de la jurisprudencia del TJUE y del Tribunal Supremo. Las pautas tradicionalmente asentadas se han visto alteradas por la irrupción en el panorama normativo de la Ley 14/2014, de 24 de julio, de Navegación Marítima (en adelante LNM) ${ }^{1}$ que introduce en el juego procesal un nuevo artículo- el 468 LNM- obligando a doctrina y jurisprudencia a reordenarse para hacer hueco a un precepto controvertido con nuevas exigencias para la validez formal de las cláusulas de jurisdicción que distorsiona la practica en el sector ${ }^{2}$.

2. Una vez admitida la heterogénea realidad normativa y asumida la interacción de bloques normativos en presencia (fuente institucional, internacional e interna), la jurisprudencia española va volviendo recuperar la línea establecida en torno a la autonomía de la voluntad de las partes en la regulación europea e internacional, mientras asimila paulatinamente la escasa repercusión practica que, finalmente, va a tener el artículo 468 de la $\mathrm{LNM}^{3}$. Así se manifiesta a través del Auto de la Audiencia Provincial de Madrid objeto de este trabajo que retoma las notas características del sistema europeo sobre las cláusulas atributivas de jurisdicción a través de una decisión que, sin plantearse dudas acerca de la normativa aplicable al caso, hace un repaso por algunas de las cuestiones más habituales en el sector de la contratación marítima.

\section{Hechos}

3. En el presente supuesto la compañía de seguros ZURICH INSURANCE PCL, sucursal en España, (en adelante ZURICH,) subrogándose en la posición jurídica de su asegurada, FRIGORIFICOS COSTA BRAVA, ejercitó acción de resarcimiento contra la mercantil AP MOLLER MAERSK (MAERSK), dedicada al transporte marítimo, ante el Juzgado Mercantil de Madrid $\mathrm{n}^{\circ} 9$ por daños padecidos en la carga transportada a encargo de su asegurada. La demandada, MAERSK, contestó con una declinatoria por falta de competencia internacional de los tribunales españoles en virtud de la existencia de una cláusula de sumisión a la High Court of Justice de Londres contenida en el conocimiento de embarque. El Juzgado Mercantil $n^{\circ} 9$ de Madrid estimó la declinatoria planteada en un Auto recurrido después en apelación por ZURICH que alega la nulidad de dicha cláusula por considerarse abusiva al venir incorporada en un conocimiento de embarque que no ha sido firmado, y que, a su juicio, evidencia la mala fe de la transportista MAERSK por pretender llevar a la asegurada de la demandante a litigar ante un tribunal extranjero con el objeto de beneficiarse del tamaño de FRIGORIFICOS COSTA BRAVA y dificultar su acceso a la justicia.

\footnotetext{
${ }^{1}$ Ley 14/2014, de 24 de julio de Navegación Marítima, BOE núm. 180 de 25 de julio de 2014.

2 J.J. Álvarez Rubio, "Entre La Haya, Hamburgo y Rotterdam: la compleja opción legislativa interna ante las cuestiones de jurisdicción y arbitraje en el Derecho marítimo", AEDIPr. n 17, 2017, pp. 597-646.

${ }^{3}$ Vid., J.J. Álvarez Rubio, "Una acertada orientación jurisprudencial en relación a la validez y alcance de la cláusula sumisoria a favor de tribunal extranjero contenido en un conocimiento de embarque. Comentario al Auto de 13 de febrero de 2019 de la AAP de Barcelona (Sección 15)", CDT, Vol. 11, n 2, 2019, pp. 388-401; M. GóMEZ JENE, "Las cláusulas de jurisdicción y arbitraje en la nueva Ley de Navegación Marítima", CDT, 2014, Vol. 6 n 2, 2014, pp. 112-129; J. M. GonZalez Pellicier,, "Sobre el artículo 468 del Proyecto de Ley de Navegación Marítima y nulidad de las cláusulas de elección del foro en los conocimientos de embarque", Diario La Ley, núm. 8354, 15.7.2014.
} 
4. La Audiencia Provincial de Madrid desestima el recurso interpuesto y, haciendo gala de la poca importancia que da a los nuevos elementos que conforman el bloque normativo en el sector, trae a colación su jurisprudencia anterior mediante una transcripción extensa del Auto de 23 de abril de 2010 que, aunque pudiera ser correcto proyectar sobre el presente, debería haber sido actualizado. En ella no sólo no ha tenido en cuenta la entrada en vigor del artículo 468 LNM (que no se aplicaba en este supuesto) si no que ha pasado por alto la importancia que tienen las novedades del Reglamento Bruselas I bis (RBIbis) y de su artículo 25 en aras a analizar la validez de las cláusulas de jurisdicción y, en este contexto, de su correlación con el artículo 468 LNM. Aun así, superado este obstáculo, la Audiencia esgrime correctamente la jurisprudencia del Tribunal de Justicia de la Unión (TJUE) vertida sobre la materia para examinar, como veremos a continuación, diversas cuestiones en torno a la determinación del Derecho aplicable y los tribunales susceptibles de elección (III); las condiciones formales de validez del acuerdo atributivo de jurisdicción (IV); y la oponibilidad de las cláusulas atributivas frente a terceros (V).

\section{Determinación del Derecho aplicable y tribunales susceptibles de elección}

\section{Determinación del Derecho aplicable a la validez de la cláusula de sumisión}

5. El punto de partida en la resolución del recurso ante la Audiencia Provincial de Madrid debe ser la determinación de la normativa aplicable a la validez de la cláusula de sumisión. Por un lado, porque su validez es lo que se discute por ambas partes como objeto de la causa y dependerá de la normativa aplicable; pero, también, porque no podemos obviar -a pesar de que sí lo haga la Audiencia- la diversidad resultante de la actual interacción entre los diversos bloques normativos y el debate existente en torno a la determinación del régimen normativo aplicable a las cláusulas atributivas de jurisdicción en el ámbito de la contratación marítima. En el sector de la contratación marítima la selección del régimen jurídico aplicable a los derechos y obligaciones de las partes y a los limites de la autonomía de la voluntad se ha convertido en un punto de partida indispensable ante el cambio de orientación recogido en el artículo 468 de la $\mathrm{LNM}^{4}$. La pugna entre la seguridad versus el favor negotti se ha reavivado con la entrada en vigor de la LNM que exige la negociación individualizada y separada de las cláusulas de competencia en aras a proteger los intereses de terceros y salvaguardar la seguridad jurídica y que, en cierto sentido, subyace bajo las distintas posturas adoptadas por las partes en el caso que nos ocupa. Por ello, a pesar de la simplificación normativa realizada por la Audiencia Provincial de Madrid, y con independencia de que el resultado final pueda ser acertado, es necesario hacer un análisis inicial de la ley aplicable a la validez de la clausula de sumisión a una jurisdicción extranjera en este caso concreto en aras a entender mejor la postura de ambas partes y la decisión final adoptada por el tribunal.

6. Como decíamos, la LNM ha incorporado especialidades procesales de jurisdicción y de competencia en el ámbito del transporte marítimo y, a través de su artículo 468, establece nuevos requisitos para las cláusulas de sumisión contenidas en los contratos de utilización del buque que, a pesar de su especialidad, van a tener que convivir con los del artículo 25 del RBIbis. Lo primero que tenemos que subrayar es que, en la interacción de ambos instrumentos, el RBIbis prevalece sobre el artículo 468 LNM cuando los tribunales extranjeros señalados por la cláusula pertenezcan a un Estado miembro de la Unión Europea ${ }^{5}$. Como consecuencia cualquier cláusula incluida en un contrato de utilización de buque que atribuya jurisdicción para conocer una controversia a un tribunal de un Estado miembro, con independencia de que las partes tengan o no su domicilio ubicado en la UE, se regirá en cuanto a su validez por lo dispuesto en el artículo 25 RBIbis. Lo segundo, es que el régimen contenido en el artículo

\footnotetext{
${ }^{4}$ Vid. J.J. Álvarez Rubio, “Entre La Haya, Hamburgo...,", op.cit., p. 26 y ss.; J. C. Fernández Rozas, “Alternativas e incertidumbres de las cláusulas de solución de controversias en la contratación marítima internacional", CDT, 2018, Vol. 10, No 2, pp. 333-375.

${ }^{5}$ Vid. F. Garau Sobrino, "Los acuerdos atributivos de jurisdicción en Derecho procesal civil internacional español", $C D T$, Vol. 2, 2010, pp. 52-91; M. Virgos Soriano/F.J. Garcimartin Alferez, Derecho procesal civil internacional. Litigación internacional. $2^{\text {a }}$ ed. Madrid, Thomson 2017, pp. 275-304.
} 
468 LNM se aplicará a aquellos casos en los que el tribunal o tribunales extranjeros designados por las partes en una cláusula atributiva de jurisdicción no pertenezcan a un Estado miembro ni a un Estado que sea parte en un Convenio Internacional en vigor en España ${ }^{6}$.

7. En este sentido, teniendo en cuenta que la cláusula de sumisión en cuestión señala la competencia de los tribunales ingleses, en concreto a la Hight Court of Justice de Londres, la validez formal de la cláusula quedará sometida, sin lugar a duda, a la regulación europea. La Audiencia llega a esta misma conclusión, pero lo hace a través de la transcripción literal de un Auto de 2010 anterior a las novedades normativas acontecidas tras su publicación. En él, se señala al Reglamento de Bruselas I (vigente entonces) para regular la competencia de los Tribunales españoles en "cuestiones que afecten a sujetos domiciliados en España y Dinamarca", y conforme a la Sentencia del Tribunal Supremo de 27 de mayo de $2008^{7}$ será "la norma internacional la que establece los requisitos de forma que deben reunir las cláusulas atributivas de competencia, en aras de la seguridad jurídica y para garantizar el consentimiento de las partes, y no el derecho español de origen interno". Sin embargo, la nueva configuración de los bloques normativos en presencia nos lleva a resaltar la desafortunada imprecisión del argumento de la Audiencia. La postura adoptada en el 2010 omite cuestiones especialmente relevantes en la actualidad que, no obstante, pasan desapercibidas. Por un lado, desconoce que el artículo 25 del RBIbis no exige que una de las partes tenga domicilio en un Estado miembro como requisito de aplicación personal y que se aplicará para analizar la validez formal de cualquier cláusula adscrita a un contrato de utilización de buque siempre que establezca la competencia de un tribunal europeo. Y, por otro, olvida que el articulo 468 LNM irrumpe con fuerza en el cuadro normativo conformando las normas de origen interno que serán aplicables cuando los tribunales designados no sean los de un Estado miembro.

\section{Tribunales susceptibles de elección}

8. Otra de las cuestiones a debate y que, en cierto modo, presenta nexos con la determinación del Derecho aplicable a la validez de la cláusula de jurisdicción, es la elección del Tribunal inglés a pesar de que el supuesto carezca de elementos de conexión con el lugar señalado ${ }^{8}$. La falta de conexión es alegada por la aseguradora como un atisbo de mala fe o fraude de ley por la porteadora que pretende llevar el litigio a dicho foro para perjudicar a su asegurada (FRIGORIFICOS COSTA BRAVA) de menor tamaño. Sin embargo, la consideración de que la demandada (MAERSK) estaría obrando con abuso de derecho con el objetivo de incomodar a la otra parte llevando el litigio ante un tribunal extranjero ajeno, en lugar de dirimirlo en su propio país, no es apoyada por la Audiencia. La carencia de vinculo con el Reino Unido no es motivo suficiente para rechazar su competencia, sobre todo si tenemos en cuenta la especialidad del foro. Las cláusulas atributivas de competencia permiten a las partes someter sus controversias a un foro neutral con el objetivo de dotar de mayor seguridad y certeza a su relación y las únicas exigencias que deben apreciarse son los estipuladas por la norma aplicable. Además, en el ámbito del Derecho marítimo las ventajas de acudir a la sumisión se incrementan en tanto facilitan las transacciones y otorgan previsibilidad a la resolución de controversias, sobre todo, como en este caso, si se acude a un tribunal especializado con gran experiencia en el sector. De hecho, la elección del tribunal inglés no suele ser una consecuencia del mayor o menor tamaño de las empresas, ni siquiera de la influencia que pudieran tener las grandes compañías navieras como habituales redactoras de las cláusulas, sino de su especialización

${ }^{6}$ J.J. Álvarez Rubio, “Una acertada orientación jurisprudencial...”, p. 12; J. C. Fernández Rozas, “Alternativas...”, p. 351-352.

7 Sentencia TS 428/2008, Sala de lo Civil Sección 1, de 27 de mayo de 2008.

${ }^{8}$ El único requisito que se exige es que el órgano señalado pertenezca a un Estado miembro y, a diferencia de las competencias especiales que se justifican en la existencia de una conexión directa con el tribunal señalado por la norma, no se requiere la existencia de ningún vínculo entre la relación jurídica y el tribunal señalado, vid.; STJ de 17 de enero de 1980, as. 59/79, “(...) el artículo 17, situado en la Sección Sexta del Convenio titulado "prórroga de la competencia" que prevé la competencia exclusiva del tribunal designado por las partes con arreglo a las formas prescritas ...y hace abstracción de cualquier elemento objetivo de conexión entre la relación objeto del litigio y el Tribunal designado..." y STJ de 16 de marzo de 1999, as. C-159/97, Castelletti. 
y larga trayectoria en litigios marítimos ${ }^{9}$. La especialidad del foro enmienda en todo caso la carencia de conexión, y el hecho de que resulte más costoso o incomodo litigar en el extranjero no es razón para obviar el efecto derogatorio de la cláusula sobre la competencia de los tribunales españoles.

9. Por su parte, la posibilidad de que se hubiera considerado que el Reino Unido no forma parte de la UE queda por el momento descartada. Así lo ha establecido recientemente la Audiencia de Barcelona, sección 15, mediante Auto de 8 de abril de $2019^{10}$, que declara como válida y aplicable una cláusula de sumisión expresa al tribunal londinense adscrita a un documento de transporte y rechaza la pretensión de nulidad de la demandante basada en la no aplicación del artículo 25 del RBIbis porque el Reino Unido ha dejado de formar parte de la UE desde el 29 de marzo ${ }^{11}$.

\section{Condiciones formales de validez del acuerdo atributivo de jurisdicción}

10. A partir del 10 de enero de $2015^{12}$ la validez de las cláusulas de sumisión al tribunal de un Estado miembro de la UE se determinará conforme al artículo 25 del RBbis. El artículo 25 RBIbis regulará la eficacia y la validez formal, mientras que la validez material se regirá por la ley de los tribunales designados por la cláusula (en este caso la ley inglesa) incluida sus normas de conflicto ${ }^{13}$. De este modo la validez del acuerdo de elección depende de la capacidad de las partes y de la acreditación de su consentimiento, y el consentimiento, entendido como condición de eficacia de la cláusula, se considera una cuestión relativa a su forma. En el contexto de la contratación marítima la mayoría de los conocimientos de embarque contienen clausulas atributivas de jurisdicción a un determinado tribunal. Se han convertido en clausulas dirigidas a facilitar la contratación internacional reduciendo las incertidumbres inherentes a la internacionalidad del contrato y dotando de mayor seguridad jurídica a las partes. Sin embargo, el hecho de que la designación de una jurisdicción se incluya en formulas de adhesión redactadas por el transportista, sin negociación previa por una de las partes, puede considerarse un desequilibrio en la relación contractual o ejercicio de poder de los transportistas frente cargadores, consignatarios y destinatarios de la mercancía ${ }^{14}$. La pugna entre la exigencia de seguridad y certeza y la autonomía de la voluntad de las partes resurge cuando una manifestación típica de libertad contractual - las cláusulas de elección de tribunal- se manifiesta a través de una expresión representativa de sus límites como pueden ser los contratos de adhesión o contratos tipo.

11. Ello es frecuente en el sector del transporte marítimo en el que los contratos de utilización de buque son a menudo contratos de carácter unilateral que no han sido resultado de una negociación individual y que pueden haber sido trasmitidos por endoso entre compradores sucesivamente e, incluso, (como sucede en el presente) puede que el cargador los reciba una vez cargada la mercancía ${ }^{15}$. La clave está en verificar la existencia efectiva del consentimiento de ambas partes y si se ha manifestado de manera clara y precisa de acuerdo con los requisitos formales exigidos -en este caso- por el artículo 25 del RBIbis ${ }^{16}$. Ciertamente la eficacia de la cláusula dependerá de su conocimiento y aceptación -tomado como reflejo de la libertad y capacidad de las partes para establecer tales cláusulas- y hace tiempo que

\footnotetext{
${ }^{9}$ En este sentido J. C. Fernández Rozas, “Alternativas...”, p. 339.

${ }^{10}$ Auto de la Audiencia Provincial de Barcelona, sección 15, 18 de abril de 2019, Roj: AAPB 8941/2019.

${ }^{11}$ Debemos tener en cuenta que en el momento en que se redacta esta Nota de Jurisprudencia el Brexit no está jurídicamente operativo; sobre las consecuencias del Brexit vid. R. Arenas GARcíA, "Consecuencias del Brexit para el Derecho Internacional privado europeo", Retos para la acción exterior de la Unión europea, Tiran lo Blanch, Valencia, 2017, pp. 249-276.

${ }^{12}$ Fecha de entrada en vigor del RBIbis, art.81.

${ }^{13}$ M. Virgos Soriano/F.J. Garcimartin Alferez, Derecho procesal ...pp. 284-286.

${ }^{14}$ El Preámbulo de la LNM es muy ilustrativo a este respecto y establece que "su objetivo es tratar de evitar los abusos detectados frecuentemente en el tráfico marítimo" sufridos por terceros poseedores de conocimientos de embarque que se ven obligados a someterse a tribunales extranjeros o a arbitrajes internacionales cuando en realidad no han negociado tales cláusulas o incluso las podían desconocer.

15 J.J. Álvarez Rubio, “Entre La Haya, Hamburgo...,", op.cit., p. 26 y ss.

16 STJ de 14 de diciembre de 1976, as. 24/76, Estasis Salotti.
} 
la forma escrita no es la única que valida el acuerdo atributivo de competencia en el sector marítimo ${ }^{17}$. Por el contrario, se han ido admitiendo una serie de prácticas frecuentes y comportamientos habituales que son aceptados como manifestaciones de voluntad si corresponden a un "uso" del comercio internacional en el que operan las partes ${ }^{18}$. El TJUE consolida una línea orientativa que ha ido flexibilizando los requisitos de validez de las cláusulas de sumisión y abala el consentimiento manifiesto por otras formas posibles que las partes tuvieran habitualmente establecidas o, incluso, cuando se haga en una forma conforme a un uso que las partes conocieren o debieran conocer y que, en dicho comercio fueran ampliamente conocidos y regularmente observados por las partes en los contratos del mismo tipo o sector comercial $^{19}$. De esta manera se concede un grado de flexibilidad que refleja una tendencia legislativa y jurisprudencial que sin renunciar a un mínimo de seguridad jurídica intenta encontrar un punto de equilibrio entre esa seguridad y el favor negotii.

12. En definitiva se concluye la validez formal de la cláusula atributiva de la competencia a los tribunales ingleses realizada por escrito en un conocimiento de embarque en tanto satisface las exigencias de la normativa europea. De hecho, en este caso particular, tal y como asevera la Audiencia Provincial de Madrid, cabe presumir el conocimiento y asunción de un clausulado como el que se presenta en un cargador que, a pesar de que recibe el documento en el mismo momento que entrega la carga para su transporte, lo hace sin mostrar la menor contrariedad hacia ninguno de los contenidos de su clausulado. Siendo notaria la naturaleza habitual de este tipo de pactos en el comercio marítimo internacional debemos tener en cuenta que la asegurada de la demandante es una empresa con más de 45 años de experiencia en la elaboración de porcino que produce más de $225.000 .000 \mathrm{kgs}$ al año y que destina el $75 \%$ de la producción a la exportación a más de 42 países de Asia, América, y Europa. Por tanto, proyectada la jurisprudencia del TJUE sobre el caso, se presume que las partes contratantes han dado su consentimiento a la cláusula atributiva de la competencia porque no cabe duda de que el comportamiento de estas corresponde a un "uso" que rige el ámbito del comercio internacional en que operan. Además, queda demostrado que la partes "habían entablado relaciones comerciales entre ellas con anterioridad o con otras partes que operaban en el sector considerado" ${ }^{20}$. Por todo ello, no resulta un requisito indispensable para su validez que la cláusula se encuentre firmada por ambas partes; a pesar de que, tal y como alega la apelante ZURICH, así se estipule en la Ley 7/1998 sobre Condiciones generales de la Contratación que no es aplicable a este supuesto.

13. Por otro lado, el hecho de que una cláusula haya sido impuesta no la convierte en abusiva ${ }^{21}$. En el debate acerca de la existencia de una parte débil en la relación entre el transportista y el cargador debe tenerse en cuenta que ambos son profesionales del sector marítimo y que el cargador no está obligado a contratar con el armador sino que puede buscar en el mercado mejores condiciones para sus intereses lo que le aleja del carácter de consumidor ${ }^{22}$. En este sentido, careciendo la asegurada FRIGORIFICOS COSTA BRAVA de carácter de consumidora nunca se podría invocar la cláusula ni atendiendo

17 J.J. Álvarez Rubio, "La dimensión procesal internacional en la Ley de Navegación marítima", AEDIPr, 2014-2015, pp. 177-178; recordamos que la redacción inicial del art. 17 del Convenio de Bruselas de 1968 subordinaba la validez de las cláusulas atributivas de competencia a la existencia de un convenio escrito o convenio verbal con confirmación escrita y fue en el Convenio de adhesión de 9 de octubre de 1978 del Reino de Dinamarca, de Irlanda y del Reino Unido e Irlanda del Norte (DO 1989, L 285) donde se introdujo la segunda frase del párrafo primero del artículo 17 que prevé que en el comercio internacional será válida la estipulación de una cláusula atributiva de competencia en una forma conforme a los usos que las partes conocieren o debieren conocer, vid: STJ 20 de febrero 1997, as. C-106/95: Mainschiffahrts-Genossenschaft (apartado 16, 19 y 20)

18 A. Recalde Castells, "Los contratos de utilización del buque", en A. Emparanza y J.M. Martin, Estudio sistemático de la Propuesta de Anteproyecto de Ley General de la Navegación Maritima, Gobierno Vasco, Dpto. De transporte y Obras públicas, 2006, pp. 415-479.

${ }^{19}$ E. Torralba Mendiola, "Las especialidades procesales de la Ley de Navegación Marítima: cláusulas de jurisdicción y arbitraje", $R D T$, N $\mathrm{N}^{\mathrm{o}} 16,2015$, pp. 121-131.

20 STJ de 16 de marzo de 1999, as. C-159/97, Castelletti.

${ }^{21}$ Sobre las limitaciones a la conclusión de acuerdos atributivos de jurisdicción F. Garau Sobrino, "Los acuerdos....", pp. 63-68.

${ }^{22}$ M. Gómez Jene, “Las cláusulas de...”, op.cit., p. 114; J. C. Fernández Rozas, en “Alternativas...”, op.cit., 357-358, hace un recorrido de la postura de la jurisprudencia española a este respecto. 
a su posible carácter abusivo ni por sus dificultades para litigar en un país extranjero. En todo caso, en la decisión comentada esta argumentación carece de sentido cuando es utilizada por la aseguradora en calidad de actora principal a sabiendas que ZURICH se caracteriza por ser una gran multinacional en el ramo del seguro.

\section{Oponibilidad frente a terceros}

14. Otra cuestión específica que se plantea habitualmente en el sector marítimo, y que también es traída a colación en este supuesto, es si los acuerdos de elección del foro entre cargador y porteador pueden producir efectos frente a terceros ${ }^{23}$. En esta ocasión se alega que BALTIMAR no es la cargadora si no la propietaria de la mercancía y, por tanto, que no está vinculada por el contrato de transporte que incluye la cláusula de sumisión puesto que había sido contratado por otra entidad. La STJUE Corek ${ }^{24}$ referida a los conocimientos de embarque trata expresamente la subrogación del tercero y establece que si, entregado el conocimiento de embarque al tercero, éste se subroga en todos los derechos y obligaciones del cargador, también lo hace en lo que a la cláusula de jurisdicción respecta. Bajo este punto de partida, la subrogación en los derechos y deberes de la parte originaria dependerá del Derecho nacional aplicable o, mejor, de las normas de Derecho Internacional privado de los tribunales que han sido designados por la cláusula de sumisión. Si por el contrario la ley designada por la norma de conflicto determina que el tercero respecto al contrato inicial no sucede a una de las partes originarias, corresponderá al órgano jurisdiccional que conoce del litigio verificar si el tercero ha dado efectivamente su consentimiento. En este caso se insiste en las conclusiones vertidas con anterioridad, según las cuales el consentimiento es innecesario cuando la cláusula en cuestión sea conforme a los usos comerciales ampliamente conocidos.

15. En la demanda de ZURICH se esgrime la condición de cargadora de su asegurada BALTIMAR a la luz del conocimiento de embarque y se ejercita una acción de reclamación contra el porteador de la mercancía por el daño sufrido por la misma durante su transporte a causa de la ruptura de la cadena de frio. De este modo la cláusula de sumisión se opone ante una reclamación planteada por la entidad aseguradora que acciona al amparo de la subrogación legal, pasando la compañía de seguros a ocupar la misma posición que tenía su asegurado. En consecuencia, la Audiencia Provincial de Madrid concluye que la aseguradora también resulta vinculada por la cláusula de sumisión contenida en el conocimiento de embarque -tomado en su texto íntegro- y en la medida que resultaba oponible frente a su asegurada BALTIMAR lo será ante ZURICH que se persona esgrimiendo sus derechos al amparo de mismo conocimiento de embarque.

16. En definitiva, acorde con la jurisprudencia del TJUE, si el tercero sucede en sus derechos a una parte originaria y pasa a convertirse en titular de todos y cada uno de los derechos y obligaciones que figuran en el contrato, no habría que verificar su consentimiento a la cláusula incluida en el contrato. Por tato no hace falta acreditar el consentimiento de la aseguradora para corroborar la eficacia de la cláusula de sumisión a los tribunales ingleses y la derogación de la competencia de los tribunales españoles.

\section{Conclusiones}

17. El Auto de la Audiencia Provincial de Madrid que se comenta en este trabajo resuelve, de manera acertada, sobre la validez de una cláusula atributiva de jurisdicción incluida en un conocimiento de embarque que otorga la competencia a la Hight Court of Justice de Londres. Para ello, en virtud de la primacía de la normativa europea, se basa en los requisitos estipulados en el artículo 25 del RBIbis y en la interpretación realizada por el TJUE, obviando las nuevas previsiones contenidas en la Ley de Navegación

\footnotetext{
23 J. C. Fernández Rozas, en “Alternativas...”, op.cit., 358-359.

${ }^{24}$ STJUE de 9 de noviembre 2000, as. C387/98, Corek.
} 
marítima. De esta forma, sin entrar en el debate sobre la delimitación de la normativa aplicable, nos remite a conclusiones vertidas, ya hace tiempo, sobre la aplicación de los requisitos de validez formal de las cláusulas atributivas de jurisdicción, rememorando una línea argumentativa que flexibiliza los requisitos de validez con la finalidad de hallar el equilibrio entre la autonomía de la voluntad y el favor negotti.

18. La Audiencia Provincial de Madrid se apoya en la jurisprudencia del TJUE a favor de la presunción de que las partes han dado su consentimiento a una cláusula de jurisdicción por corresponderse con un "uso" generalizado en el sector en el que operan y que las partes o conocen o debieran conocer. De este modo, desestima el recurso de apelación de la aseguradora, y acepta la validez de la cláusula integrada en un conocimiento de embarque, a pesar de que no ha sido conocida por el cargador hasta su llegada a puerto, por constituir un comportamiento habitual en el comercio marítimo que no requiere más prueba.

19. Se trata de un razonamiento que choca frontalmente con los criterios establecidos en la Ley de Navegación marítima española que demanda la negociación individual de estas cláusulas. Y nos sirve para poner de manifiesto la falta de coordinación existente entre la norma origen interno y la norma europea imbuida en una línea interpretativa más amplia de las cláusulas de foro basada en los usos y prácticas comerciales marítimas. 